\title{
Advanced coating of Tank Interior as means of Rising Environmental Safety of Tankers/RIM technology
}

\author{
Janusz Datta \\ Józef T. Haponiuk \\ Gdańsk University of Technology
}

\begin{abstract}
The application of Reaction Injection Molding (RIM) technique for forming an elastic polyurethane coating that displays selected strength characteristics, and chemical and thermal resistance is described. The study was conducted on technical-scale using a mixing-dosing device that allowed direct dosing of liquid polyurethane system into the steel bulkhead, onto the steel surfaces, and the formation of polyurethane coating. Hard coating formed after polymer gelation and crosslinking. The elaborated technology also allowed joining of ceramsite concrete which resulted in the sandwich costruction consisting of steel, concrete and polyurethane.
\end{abstract}

Keywords: polyurethane elastomers, RIM, applications

\section{INTRODUCTION}

Reaction Injection Molding (RIM) method used in this study allows the fast forming of objects from the liquid reactive components of low viscosity. Low viscosity of the reaction mix allows for obtaining the objects under low pressure (from 5 to 8 bar) at the temperature most frequently ranging from 60 do $90^{\circ} \mathrm{C}$. The increase in temperature during the process is advantageous because it results in up to even 20 -fold lower energy use. It is possible to produce large objects in short production cycles, and to automate the process. RIM methos allows forming of polyurethane products that have significantly different properties which results from varying composition of the used components, interfering into the reactions, introduction of fillers, and foaming of material. Therefore it is possible to obtain solid as well as microporous materials. It is of great value that there are no byproducts and low volume of scrap produced in the reaction; scrap generation depends on how many times the system is poured onto the mold as each such operation results in $200 \mathrm{~g}$ of waste. Therefore it is advantageous to use continous pouring in multi-mold casting apparatus (for example, of centrifugal type) because the scrap volume in relation to the produced objects is negligable. Each reactive injection process consists of a number of unit operations, e.g. preliminary mixing, storage, dosing, mixing proper and mold casting.

Mixing-dosing device used with RIM method consists of characteristic subunits that are presented in Fig. 1.

In low-pressure apparatus the metering pumps (e.g. Viking) are used that secure the required accuracy of dosing for specific components (ca. $0.5 \%$ ). The highest precision of dosing is obtained for constant viscosity and identical mass ratio of components in the reaction mix. The obtaining of polyurethane elastomers can be achieved via one step or two

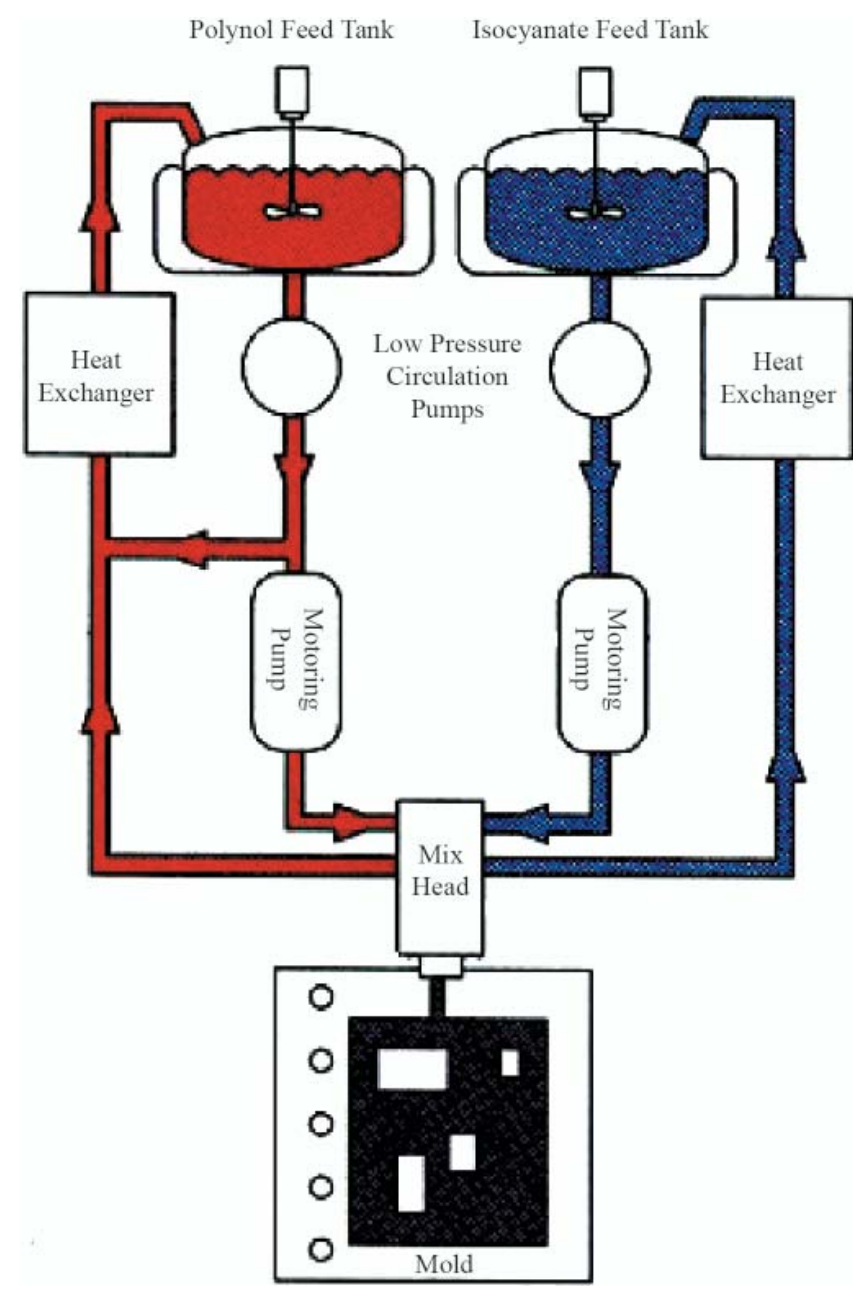

Fig. 1. Schematic presentation of mixing-dosing device [7] 
step (prepolymer) method. The two step method usually allows for producing the objects with better properties; step one is the synthesis of prepolymer. Stochiometric ratios are chosen in such a way as to retain a small surplus of diisocyanate groups (Fig. 2) in relation to oligomerol. Thus the chains in the obtained prepolymer have terminal -NCO groups. Chemical stability of such semiproduct amounts to couple hours at $80-95^{\circ} \mathrm{C}$, and to a week at $0^{\circ} \mathrm{C}$. The addition of stabilizers, e.g. orthofosforic acid, can extend the stability. Too long storage of prepolymer at high temperature results in chain degradation, and that in turn leads to worsening of mechanical strength characteristics of the obtained elastomers.

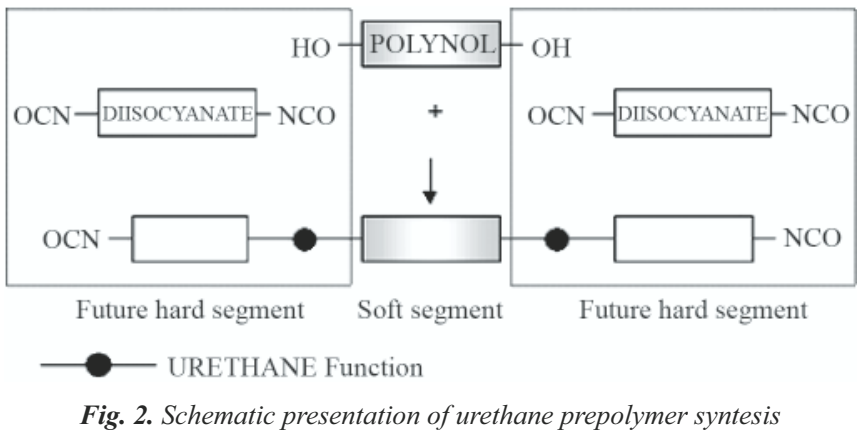

The second step is the synthesis of the molded urethane elasomer. To this end, the obtained prepolymer is extended with the small-size molecules of glycol or diamine. The mixing of components is performed by means of the mix head turbine of the mixing-dosing device. Mixing time usually amounts to couple seconds. The obtained clear polyurethane system is dispensed into the steel molds. After gelation and preliminary hardening, the material undergoes crosslinking at raised temperature, and next, it is molded. The RIM technology is a specific type of polyurethane system processing. The advantage of RIM (low pressure type) over the traditional injection molding of different polymers lies in the low viscosity of the material used. A comparison of the aforementioned technologies is presented in Tab. 1 .

Tab. 1. Comparison of parameters used in the processing of polyurethane systems and thermoplasts [1]

\begin{tabular}{|c|c|c|c|}
\hline \multicolumn{2}{|c|}{ Parameter } & RIM & Injection molding \\
\hline $\begin{array}{c}\text { Temperature } \\
\text { of }\left[{ }^{\circ} \mathrm{C}\right]\end{array}$ & reagents & $\approx 60$ & $200 \div 300$ \\
\cline { 2 - 4 } & mold & $\approx 70$ & room temperature \\
\hline Injection pressure $[\mathrm{MPa}]$ & $<40$ & $70 \div 150$ \\
\hline \multicolumn{2}{|c|}{ Closing force $[\mathrm{Pa}]$} & 0.3 & $60 \div 130$ \\
\hline $\begin{array}{c}\text { Viscosity of material } \\
{[\mathrm{Pa} \cdot \mathrm{s}]}\end{array}$ & $0.01-1$ & $10^{2} \div 10^{5}$ \\
\hline
\end{tabular}

\section{EXPERIMENTAL PART}

\section{Materials}

4,4'- diphenylmethane diisocyanate (MDI), liquid, filterpurified, manufactured by Borsdochem (Hungary); oligo (ethylene-butylene adipate) (POLES 55/20) molecular mass 2000, manufactured by Organika - Zachem S.A. (Poland); butylene glycol (BDO) manufactured by BASF (Germany); 1,6-hexanediol (HDO) manufactured by Du Pont, (USA); 1,3- propanodiol, manufactured by POCh (Poland); ethylene glycol (GE), manufactured by POCh (Poland); oligo(oxyethylene)diol (PEG 300) manufactured by Aldrich-Chemie (Germany); orthophosphoric acid manufactured by POCh (Poland); carbodiimide, anhydric agent manufactured by Sigma Aldrich (Germany).

Catalysts: 1,4-diazabicyclo[2.2.2] octane (DABCO) manufactured by Hondry-Hüls (Germany); potassium acetate (KAc) manufactured by POCh (Poland); sodium hydroxide $(\mathrm{NaOH}) \mathrm{CIL}$ bonding agents. (Ep).

Bonding agents: Tixon 405 (T), Cilbond 45SF (C), Epoxid

\section{Measurements}

The measurements of steel surface roughness were performed using a Taylor Hobson Surtronic 10 meter gauge. The analyses were conducted at 7 points on the surface of 100x10x2 mm dimension, at room temperature. A measurement consisted of a surface scan and the reading of the roughness parameter $\mathrm{R}_{\mathrm{a}}$. The parameter $\mathrm{R}_{\mathrm{z}}$ was calculated on the basis of $\mathrm{R}_{\mathrm{a}}$ value.

Tensile elongation of polyurethane samples was assessed by means of a Zwick Z20 testing machine and according to the standard procedure PN-EN ISO 527-1:1998. Testing was carried out at room temperature, at a rate of $200 \mathrm{~mm} / \mathrm{min}$ and a force reaching up to $1000 \mathrm{~N}$.

The polyurethane hardness was measured with an HPE Shore A durometer (Zwick/Roell) and according to the PN - ISO 868:2004 standard procedure. The following parameters were used: calibrated spring force $806.5 \mathrm{cN}$, applied force $12.5 \mathrm{~N}, 35^{\circ}$ indenter, $25 \mathrm{~mm}$ path, measuring range: $0-100$, type A hardness scale, accuracy \pm 0.5 SHORE, and temperature ca. $22^{\circ} \mathrm{C}$.

\section{Apparatus}

An EC-305 mixing-dosing device (SECMER, France); system temperature $80^{\circ} \mathrm{C}$; extender temperature $40^{\circ} \mathrm{C}$. The object ready for coating was kept at room temperature; prepolymer pressure 5bar; BDO pressure 5.5bar; efficiency $2.5 \mathrm{~kg} / \mathrm{min}$.

\section{Results}

The application of RIM technique for producing elastic coating on the steel-concrete constructions

The chemical composition and conditions for dosing of liquid polyurethane system destined as elastic protective coating have been established. Selected parameters are shown in Tab. 2.

Tab. 2. Conditions for the synthesis of polyurethane elastomer destined as elastic coating, by means of a EC 305 mixing-dosing device

\begin{tabular}{|c|c|c|c|c|}
\hline No & $\begin{array}{c}{[\mathbf{N C O}] /} \\
{[\mathbf{O H}]} \\
\text { ratio }\end{array}$ & $\begin{array}{c}\text { BDO/100g } \\
{[\mathbf{g}]}\end{array}$ & $\begin{array}{c}\text { Gelation } \\
\text { time } \\
{[\mathbf{s}]}\end{array}$ & $\begin{array}{c}\text { Hardness } \\
{\left[{ }^{\mathbf{0}} \mathbf{S h} \mathbf{A}\right]}\end{array}$ \\
\hline 1 & 0.90 & 8.3 & 300 & 75 \\
\hline 2 & 0.95 & 7.9 & 310 & 80 \\
\hline 3 & 1.0 & 7.5 & 315 & 82 \\
\hline 4 & 1.05 & 7.1 & 320 & 85 \\
\hline 5 & 1.10 & 6.8 & 320 & 81 \\
\hline 6 & 1.20 & 6.5 & 325 & 80 \\
\hline
\end{tabular}


The applied study was conducted with the use of different sample models. Before each coating of the preped samples, the quality of the polyurethane system was controlled via pouring of a reference sample. sample. The reference samples had constant $[\mathrm{NCO}]:[\mathrm{OH}]$ molar ratios ranging from 0.95 to 1.10 ; their hardness was measured directly after the heat treatment.

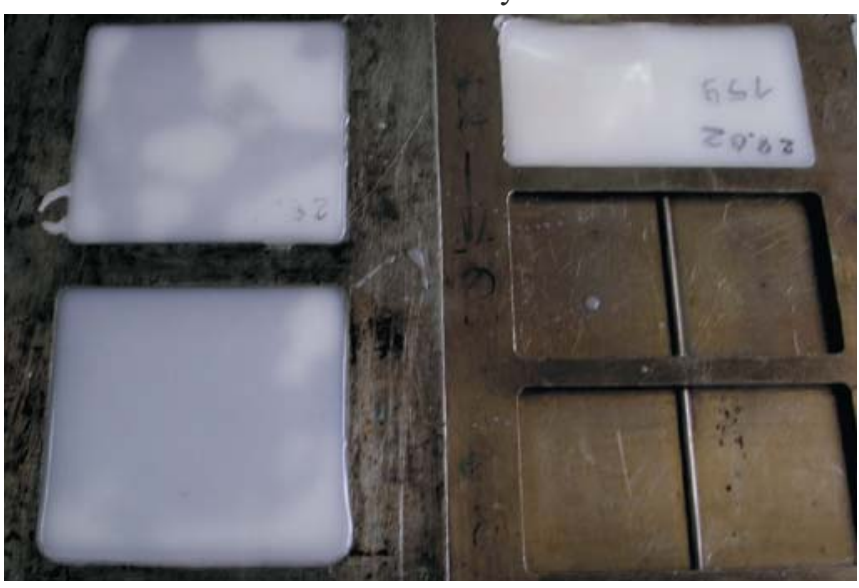

Fig. 3. Polyurethane reference samples

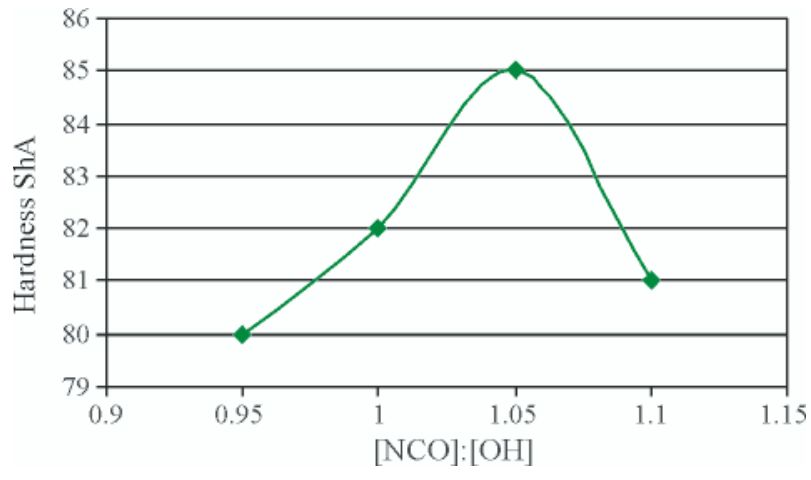

Fig. 4. Relationship between the chemical composition and hardness of obtained PU elastomers.

The selected polyurethane system was used to obtain layered samples for peel strength determination. Tab. 3 contains the information on how the polyurethane-steel sandwich samples were prepared for peel strength testing.

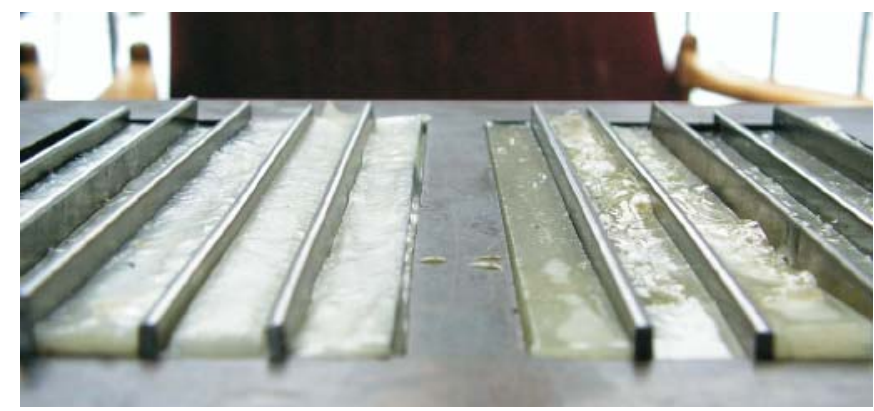

Fig. 5. Type C samples used in studying resistance to delamination

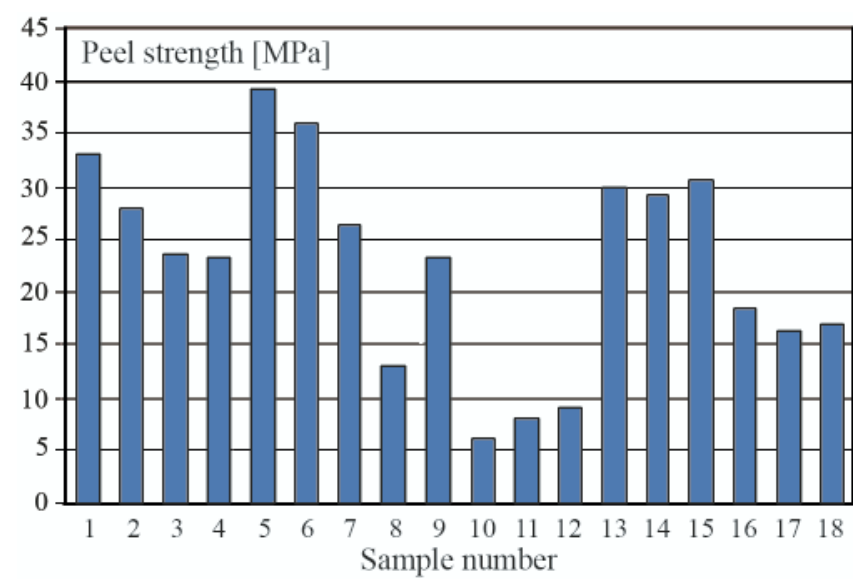

Fig. 6. Influence of surface type and adhesive on resistance to delamination in type $C$ polyurethane-steel sandwich samples

Based on the data from previous studies, conducted within the same project, the task of coating the large-size samples with elastomers was undertaken in the second stage of research.

Tab. 4. Roughness of steel surfaces coated with polyurethane

\begin{tabular}{|c|c|c|}
\hline Symbol of large-size sample & $\mathrm{R}_{\mathrm{a}}[\mu \mathrm{m}]$ & $\mathrm{R}_{\mathrm{z}}[\mu \mathrm{m}]$ \\
\hline SWR 1 & 14.1 & 56.1 \\
\hline SWR 2 & 16.4 & 65.6 \\
\hline SNR*(reference sample) & 0.3 & 1.2 \\
\hline
\end{tabular}

Based on the obtained results, it has been confirmed that the preparation of a steel surface via abrasive blasting has a big influence on the strength of the polyuretahne-steel joining. Based on the results of testing for the susceptibility to cutting (A), tearing (B) and delamination (C), the conditions for coating of large-size steel and steel-concrete samples were elaborated. The examples of large-size steel-ceramic dumbbel samples (Figs. 5-8), used for strength testing, are shown below. These samples were used to assess the mechanical strength and the behavior of elastomer during elongation. Mechanical testing was performed using the special equipment at the Faculty of Ocean Engineering and Ship Technology, Department of Ship Manufacturing Technology, Quality Systems and Materials Science, Gdansk University of Technology.

The results of the conducted studies allowed for optimization (in reference to gelation time and temperature of the system) of the procedure for coating the main reseach object with the elastomer layer. The polyurethane system under specific conditions was low-pressure sprayed with the mixing-dosing device onto the steel construction that contained concrete coated with an epoxy resin.

Tab. 3. Conditions for obtaining polyurethane-steel sandwich samples (C) to be used in the peel strength testing.

\begin{tabular}{|c|c|c|c|c|c|c|c|c|c|c|c|c|c|c|c|c|c|c|}
\hline $\begin{array}{c}\text { Sample } \\
\text { symbol }\end{array}$ & 1 & 2 & 3 & 4 & 5 & 6 & 7 & 8 & 9 & 10 & 11 & 12 & 13 & 14 & 15 & 16 & 17 & 18 \\
\hline Adhesive & - & - & - & $\mathrm{Ep}$ & $\mathrm{Ep}$ & $\mathrm{Ep}$ & $\mathrm{T}$ & $\mathrm{T}$ & $\mathrm{T}$ & - & - & - & $\mathrm{Ep}$ & $\mathrm{Ep}$ & $\mathrm{Ep}$ & $\mathrm{T}$ & $\mathrm{T}$ & $\mathrm{T}$ \\
\hline $\begin{array}{c}\text { Mechanical } \\
\text { treatment }\end{array}$ & $\mathrm{C}^{*}$ & $\mathrm{C}$ & $\mathrm{C}$ & $\mathrm{C}$ & $\mathrm{C}$ & $\mathrm{C}$ & $\mathrm{C}$ & $\mathrm{C}$ & $\mathrm{C}$ & - & - & - & - & - & - & - & - & - \\
\hline
\end{tabular}

*C- corundum 


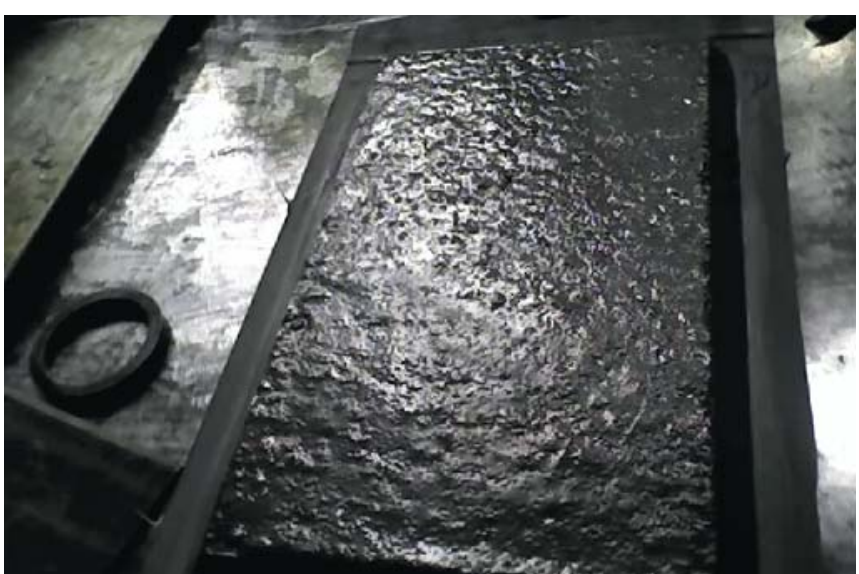

Fig. 7. Ceramic-coated sample inside the steel mold before the application of polymeric layer. Ceramic surface unpreped

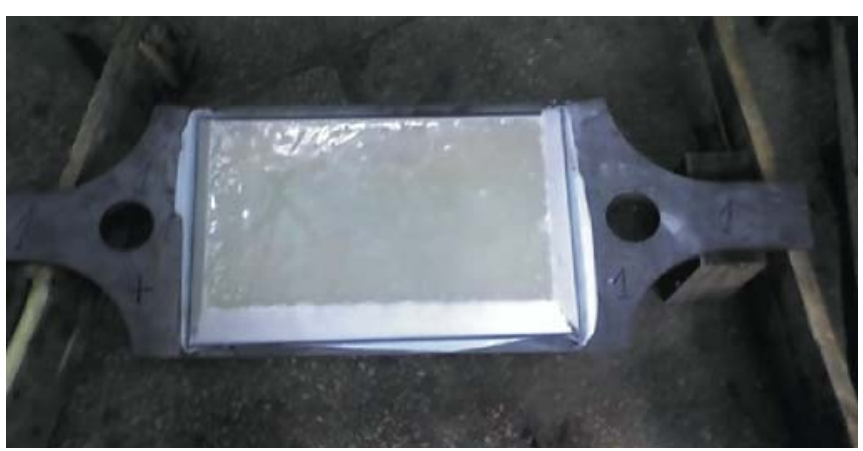

Fig. 8. Sample coated with polyureathane via RIM technique to be used for mechanical strength testing

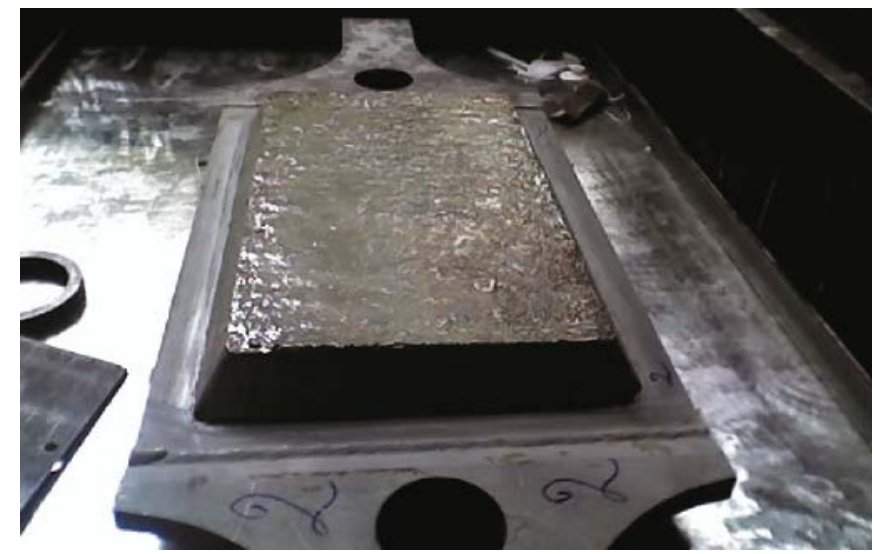

Fig. 9. Ceramic-coated sample inside the steel mold before the application of polymeric layer. Ceramic surface has been preped

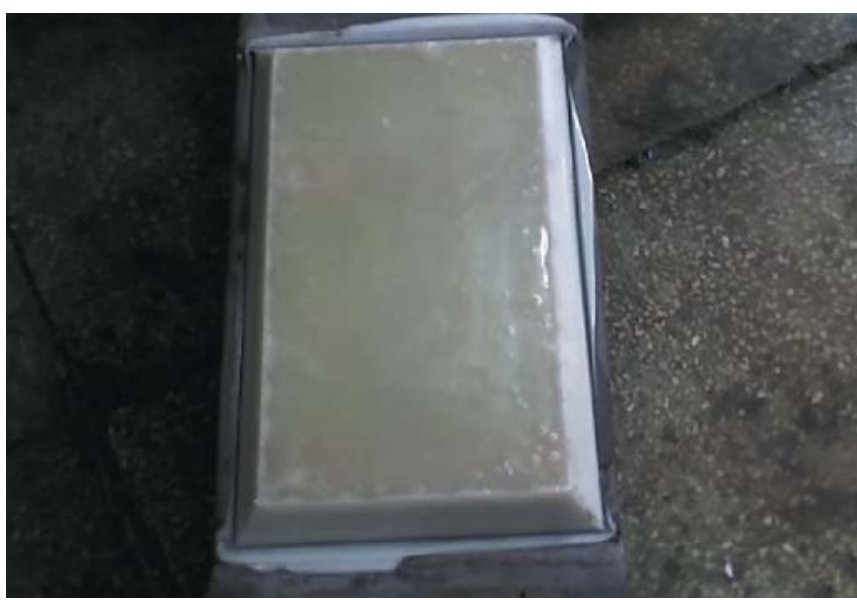

Fig. 10. Sample coated with polyureathane via RIM technique to be used for mechanical strength testing
The technology developed by us for applying the polyurethane protective coating does not employ adhesives to join polyurethane with a ceramic material. It only makes use of the high roughness of the concrete surface. The preliminary heating of the research object has not been applied either.

\section{SUMMARY}

The elaborated technology for coating the steel-concrete sandwich constructions with polyurethane elastomer via RIM method allows direct forming of the elastic layer on a given object. The produced coating has specific mechanical strength and chemical resistance. The polyurethane system applied to various surfaces (e.g. steel, concrete) by means of a mixingdosing device allows for obtaining layers of specified thickness that properly adhere to the substrate.

\section{BIBLIOGRAPHY}

1. Wirpsza Z.: Polyurethanes chemistry technology of applying (in Polish). WNT, Warszawa 1991

2. Datta J., Kania E., Krajewski G., Haponiuk J.T.: Analysis of strength of polyurethane-steel layers, XLIX Zjazd PTChem i SITPChem, Gdańsk, 18-22 September 2006

3. Datta J., Łaski M., Kucińska-Lipka J.: The properties of polyurethane elastomers to be used as polymer cores in sandwich plate systems (SPS). Przem. Chem. 2007, 86, 63.

4. Datta J., Laski M., Witkiewicz W.: The polymer-steel sandwich plate systems (SPS). Przem. Chem. 2007, 86, 200

5. Datta J, Bielińska M.: Effect of ceramsite on properties of cast urethane elastomers. Przem. Chem. 2007, 86, 663

6. Haponiuk J., Strankowski M., Datta J.: The latest developments in chemistry and technology of thermoplastic polyurethane elastomers, „Pomerania - Plast” Scientific Conference, 23-25 May 2007, Szczecin-Kołobrzeg. Seminar material.

7. http://plastics.turkavkaz.ru/processes/molding/injectionmolding/reaction/

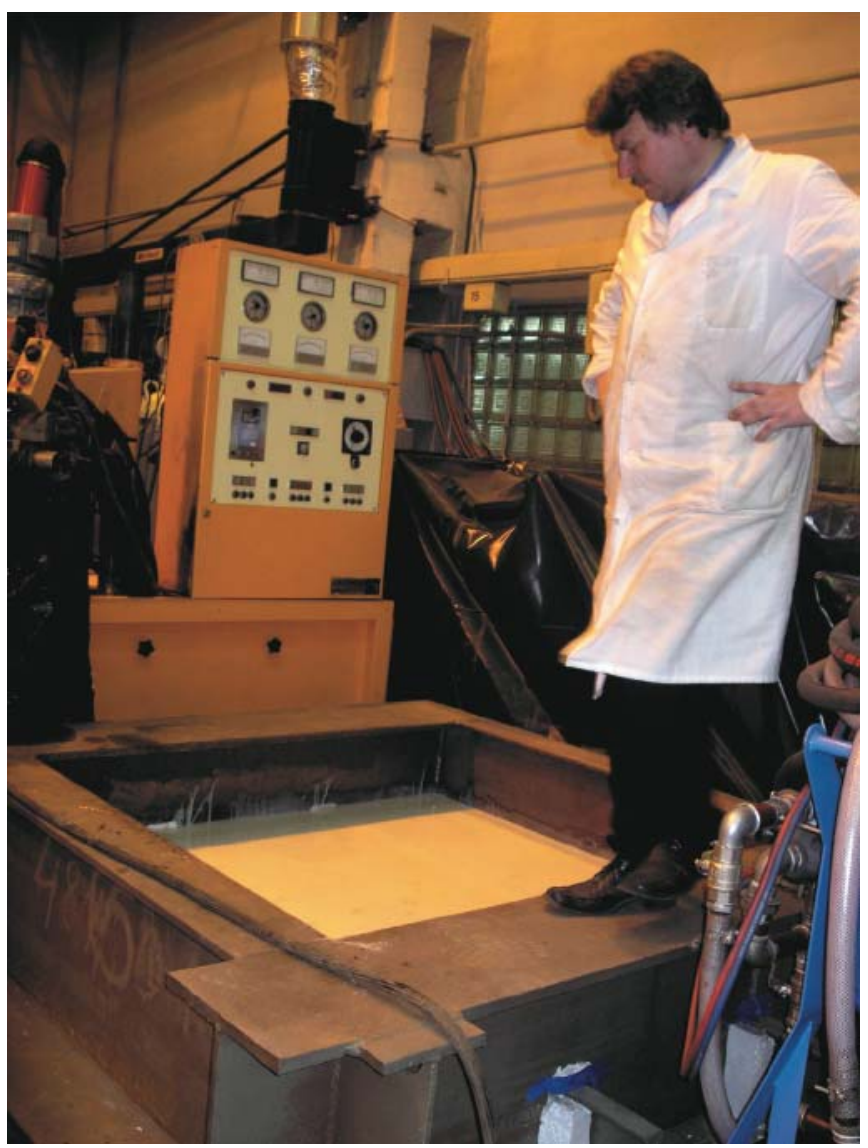

Elastomer layer on the steel-concrete object 